\title{
ANALISIS PENDEKATAN LINE BALANCING MENGGUNAKAN METODE RANGKED POSITION WEIGHTS, LARGEST CANDIDATE RULE DAN J-WAGON PADA PROSES PRODUKSI KAUS SABRINA COLLECTION
}

\author{
Ghufron \\ Teknik Industri, Fakultas Sains dan Teknologi, Universitas Al-Azhar Indonesia \\ Komplek Masjid Agung Al-Azhar, Jalan Sisingamangaraja Kebayoran Baru, Jakarta Selatan 12110, Indonesia \\ e-mail: Ghufronharvey@gmail.com
}

\begin{abstract}
ABSTRAK
Di era yang serba maju ini banyak perusahaan manufaktur harus bisa untuk terus meningkatkan kualitas dan kuantitas produksi sehingga bisa terus melayani permintaan konsumen dengan lebih baik. Namun masih banyak terdapat masalah yang dihadapi perusahaan untuk meningkatkan kualitas dan kuantitas produksinya seperti yang terjadi pada perusahaan konveksi Sabrina Collection perusahaan dibidang konveksi ini memiliki masalah pada proses produksi dimana masih banyak bottleneck yang terjadi dan masih adanya tenaga pekerja yang tidak bekerja sesuai jobdesk yang tersedia dikarenakan banyaknya bootleneck. Pada masalah ini peneliti ingin meneliti dibagian mana saja bottleneck tersebut terjadi dan bagaimana cara menguranginya pada penelitian kali ini peneliti menggunakan pendekatan yaitu Line Balancing dengan metode rangked positional weights, largest candidat rules dan $j$ wagon. Setelah dilakukan penelitian dan pengolahan data peneliti mendapatkan nilai paling optimal yaitu dengan menggunakan metode largest candidat rules dan j-wagoon dengan waktu siklus sebesar 20 menit.
\end{abstract}

Kata kunci: Line Balancing, Bottleneck, Waktu Siklus, Konveksi.

\section{ABSTRACT}

In this highly developed era, many manufacturing companies must be able to continue to improve the quality and quantity of production so that they can continue to serve consumer demand better. But there are still many problems faced by companies to improve the quality and quantity of production as happened in the Sabrina Collection convection company. This company in the convection field has problems in the production process where there are still many bottlenecks that occur and there are still workers who do not work according to the available jobdesk due to many bootlenecks. In this problem the researcher wants to examine where the bottleneck occurs and how to reduce it in this study the researchers used an approach that is Line Balancing with the method of ranking positional weights, largest candidat rules and j-wagon.. After conducting research and data processing the researcher gets the most optimal value by using the largest candidat rules and j-wagoon method with a cycle time of 20 minutes.

Keywords: Line Balancing, Bottlenecks, Cycle Times, Convection.

\section{PENDAHULUAN}

Pada era globalisasi ini, perusahaan manufaktur harus terus menerus meningkatkan proses dalam sistem produksinya, agar dapat meningkatkan kualitas dan kuantitas produksi, sehingga bisa melayani konsumen dengan lebih baik lagi. Purnomo [1] menjelaskan jika perencanaan dan pengaturan yang tidak tepat dapat mengakibatkan setiap stasiun kerja pada lintas perakitan memiliki kecepatan produksi yang berbeda sehingga terjadi penumpukan material di antara stasiun kerja yang tidak berimbang kecepatan produksinya (bottleneck). Oleh karena itu perlu dilakukan usaha-usaha untuk menyeimbangkan lintasan produksi (line balancing) [2,3].

Sabrina Collection yang menjadi salah satu produsen garmen yang berlokasi di Bogor, Jawa Barat. Sandang merupakan kebutuhan pokok yang harus dimiliki manusia. Banyak sekali perusahaan di bidang ini dan banyak sekali saingannya. Kaus termasuk salah satu dari tiga kebutuhan pokok, yaitu sandang. Adanya permintaan yang sangat tinggi, menuntut Sabrina collection untuk memenuhi permintaan dengan memproduksi dalam jumlah banyak dan kualitas yang baik. 
Untuk bisa memproduksi kaus dalam jumlah besar dan tepat waktu, harus diterapkan metode line balancing yang efisien di lini produksi, agar setiap stasiun kerja yang ada di lini produksi dapat menyelesaikan pekerjaan sesuai dengan waktu yang telah ditentukan. Selain itu, line balancing juga menentukan serta menyeimbangkan elemen kerja di setiap stasiun kerjanya, agar setiap operator memiliki beban kerja dan waktu yang seimbang sehingga tidak terjadi bottleneck atau penumpukan. Dalam tulisan ini, difokuskan analisis line balancing pada divisi produksi dari awal pembuatan hingga akhir pembuatan kaus.

\section{METODE PENELITIAN}

Dalam penelitian ini analisis di lakukan dengan menggunakan line balancing. Line balancing merupakan penyeimbangan penugasan elemen tugas dari suatu assembly line ke work stations untuk meminimumkan banyaknya work stations dan meminimumkan total idle time pada semua stasiun pada tingkat output tertentu $[4,5,6]$. Beberapa metode line balancing, yang di gunakan diantaranya seperti Metode Rangked Positional Weights $(R P W)$, metode ini merupakan metode gabungan antara Metode Large Candidat Ruler dengan Metode Region Approach untuk analisis Line Balancing [7]. Metode lainnya adalah Metode Largest Candidate Rules, metode ini melakukan pendekatan penyeimbangan lini produksi berdasarkan waktu operasi terpanjang akan diprioritaskan penempatannya dalam stasiun kerja. Prinsip dasarnya adalah menggabungkan prosesproses atas dasar pengurutan operasi dari waktu proses terbesar. Untuk Metode J-Wagon, metode heuristik ini mengutamakan jumlah elemen kerja yang terbanyak, dimana elemen kerja tersebut akan diprioritaskan terlebih dahulu untuk ditempatkan dalam stasiun kerja dan diikuti oleh elemen kerja lain yang memiliki jumlah elemen kerja yang lebih sedikit. Metode heuristik ini mengutamakan jumlah elemen kerja yang terbanyak, dimana elemen kerja tersebut akan diprioritaskan terlebih dahulu untuk ditempatkan dalam stasiun kerja dan diikuti oleh elemen kerja lain yang memiliki jumlah elemen kerja yang lebih sedikit $[8,9,10]$. Tetapi yang perlu diperhatikan sebelum menggunakan semua metode diatas untuk menyeimbangkan lintasan produksi, adalah menyelesaikan terlebih dahulu akar permasalahan yang menjadi penyebab ketidakseimbangan lintasan produksi tersebut [11].

\section{HASIL DAN PEMBAHASAN}

Observasi terhadap pekerja di perusaan Sabrina Collection dengan mengamati proses pembuatan kaus, didapatkan data waktu siklus. Waktu siklus setiap stasiun kerja juga diambil datanya dengan melakukan wawancara dan perhitungan langsung menggunakan stopwatch. Waktu siklus ini digunakan sebagai data yang digunakan untuk proses pengolahan data. Berikut waktu siklus dapat dilihat pada Tabel 1.

Tabel 1. Waktu Siklus

\begin{tabular}{clc}
\hline No & \multicolumn{1}{c}{ Proses } & Waktu \\
\hline 1 & Persiapan & 5 \\
2 & Membuat Pola Lengan & 5 \\
3 & Membuat Pola Body & 10 \\
4 & Membuat Pola Leher & 5 \\
5 & Pemotongan Pada Bag. Lengan & 6 \\
6 & Pemotongan Pada Bag. Body & 13 \\
7 & Pemotongan Pada Bag. Leher & 4 \\
8 & Penjahitan Pada Bag. Lengan & 3 \\
9 & Penjahitan Pada Bag. Body & 15 \\
10 & Penjahitan Pada Bag. Leher & 3 \\
11 & Pengkleman Pada Lengan & 6 \\
12 & Penyablonan Pada Body & 20 \\
13 & Pengkleman Pada Leher & 3 \\
14 & Pembordiran Pada Body & 15 \\
15 & Pemeriksaan & 3 \\
\hline
\end{tabular}


Berdasarkan proses produksi pada setiap stasiun kerja, diambil data informasi mengenai LRP yaitu waktu nama part, nomor part, material, nomor operasi, ukuran, deskripsi operasi, mesin, yang digunakan, setup time, reliabilities, tools, dan scrap. Berikut datanya dapat dilihat pada Tabel 2, yang berisi lembar rencana proses pada bagian lengan, Tabel 3 berisi lembar rencana proses pada bagian leher, Tabel 4 berisi lembar rencana proses pada bagian badan, sampai dengan Tabel 5, yang berisi lembar rencana proses assy seluruh bagian.

Tabel 2. Lembar Rencana Proses pada Bagian Lengan

\begin{tabular}{|c|c|c|c|c|c|c|c|}
\hline Nama Part & Lengan & & & & & Panjang & $50 \mathrm{~cm}$ \\
\hline Nomor Part & 100 & & & & Ukuran & Lebar & $20 \mathrm{~cm}$ \\
\hline Material & Kain & & & & & Tebal & $2 \mathrm{~mm}$ \\
\hline No.Operasi & Deskripsi Operasi & Mesin & Setup Time & Run Time & Reliabilitas & Tools & Scrap \\
\hline 101 & Membuat Pola & & 0 & 10 & & Kapur Jahit & $0 \%$ \\
\hline 102 & Pemotongan & & 0 & 10 & $3 \%$ & Gunting & $5 \%$ \\
\hline 103 & Jahit & Mesin jahit & 10 & 30 & $3 \%$ & & $3 \%$ \\
\hline 104 & Diklem & Mesin jahit & 10 & 15 & $2 \%$ & & $0 \%$ \\
\hline
\end{tabular}

Tabel 3. Lembar Rencana Proses pada Bagian Leher

\begin{tabular}{|c|c|c|c|c|c|c|c|}
\hline Nama Part & Lengan & & & & & Panjang & $50 \mathrm{~cm}$ \\
\hline Nomor Part & 200 & & & & Ukuran & Lebar & $20 \mathrm{~cm}$ \\
\hline Material & Kain & & & & & Tebal & $2 \mathrm{~mm}$ \\
\hline No.Operasi & Deskripsi Operasi & Mesin & Setup Time & Run Time & Reliabilitas & Tools & Scrap \\
\hline 201 & Membuat Pola & & 0 & 5 & & Kapur Jahit & $0 \%$ \\
\hline 202 & Pemotongan & & 0 & 5 & $3 \%$ & Gunting & $3 \%$ \\
\hline 203 & Jahit & Mesin jahit & 10 & 5 & $3 \%$ & & $3 \%$ \\
\hline 204 & Diklem & Mesin jahit & 10 & 5 & $2 \%$ & & $0 \%$ \\
\hline
\end{tabular}

Tabel 4. Lembar Rencana Proses pada Bagian Badan

\begin{tabular}{|c|c|c|c|c|c|c|c|}
\hline Nama Part & Lengan & & & & & Panjang & $150 \mathrm{~cm}$ \\
\hline Nomor Part & 300 & & & & Ukuran & Lebar & $75 \mathrm{~cm}$ \\
\hline Material & Kain & & & & & Tebal & $2 \mathrm{~mm}$ \\
\hline No.Operasi & Deskripsi Operasi & Mesin & Setup Time & Run Time & Reliabilitas & Tools & Scrap \\
\hline 301 & Membuat Pola & & 0 & 15 & & Kapur Jahit & $0 \%$ \\
\hline 302 & Pemotongan & & 0 & 20 & $5 \%$ & Gunting & $10 \%$ \\
\hline 303 & Jahit & Mesin jahit & 10 & 30 & $3 \%$ & & $5 \%$ \\
\hline
\end{tabular}

Tabel 5. Lembar Rencana Proses Assy Seluruh Bagian

\begin{tabular}{|c|c|c|c|c|c|c|c|}
\hline Nama Part & Leher+Body+Lengan & & & & & Panjang & $250 \mathrm{~cm}$ \\
\hline Nomor Part & 400 & & & & Ukuran & Lebar & $115 \mathrm{~cm}$ \\
\hline Material & Kain & & & & & Tebal & $2 \mathrm{~mm}$ \\
\hline No.Operasi & Deskripsi Operasi & Mesin & Setup Time & Run Time & Reliabilitas & Tools & Scrap \\
\hline 401 & Perakitan & & 0 & 20 & & Mesin jahit & $0 \%$ \\
\hline 402 & Inspeksi & & 0 & 15 & & & $0 \%$ \\
\hline 403 & Packaging & & 0 & 20 & $3 \%$ & & $0 \%$ \\
\hline
\end{tabular}

Salah satu Metode Line Balancing yang digunakan peneliti untuk mengolah data informasi yang sudah didapat yaitu Metode RPW (Rangked Positional Weights) untuk menghitung antar elemen kerja dengan posisi masing-masing elemen kerja dalam Precedence Diagram. Serta meminimasi stasiun kerja yang sudah ada menjadi lebih efektif dengan cara mengelompokkan stasiun yang sekiranya bisa dikelompokan dengan stasiun yang berdekatan sehingga bisa menjadi satu kelompok dan bisa memotong waktu produksi. Berikut hasil pengolahan data waktu di Metode RPW dapat dilihat pada Tabel 6 dan Tabel 7. 
Tabel 6. Waktu Siklus Setiap Stasiun Kerja

\begin{tabular}{cc}
\hline Stasiun Kerja & Waktu Siklus \\
\hline 1 & 5 \\
2 & 5 \\
3 & 10 \\
4 & 5 \\
5 & 6 \\
6 & 13 \\
7 & 4 \\
8 & 3 \\
9 & 15 \\
10 & 3 \\
11 & 6 \\
12 & 20 \\
13 & 3 \\
14 & 15 \\
15 & 3 \\
\hline Total & 116 \\
\hline
\end{tabular}

Tabel 7. Tabel Hasil Data Setelah Diolah Menggunakan Metode RPW

\begin{tabular}{|c|c|c|c|}
\hline Stasiun Kerja & Waktu Siklus & Waktu Baku & Waktu Total \\
\hline 1 & 116 & 5 & \multirow{2}{*}{15} \\
\hline 3 & 71 & 10 & \\
\hline 6 & 61 & 13 & 13 \\
\hline 9 & 48 & 15 & \multirow{2}{*}{20} \\
\hline 2 & 38 & 5 & \\
\hline 4 & 33 & 5 & 5 \\
\hline 12 & 33 & 20 & 20 \\
\hline 5 & 33 & 6 & \multirow{4}{*}{16} \\
\hline 7 & 28 & 4 & \\
\hline 8 & 27 & 3 & \\
\hline 10 & 24 & 3 & \\
\hline 11 & 24 & 6 & \multirow{3}{*}{14} \\
\hline 13 & 21 & 3 & \\
\hline 14 & 18 & 5 & \\
\hline \multirow[t]{2}{*}{15} & 13 & 13 & 13 \\
\hline & $\begin{array}{l}\text { Line Efficiency } \\
\text { Smoothing Index }\end{array}$ & $\begin{array}{r}82.857143 \\
20\end{array}$ & \\
\hline
\end{tabular}

Dari hasil waktu siklus yang dihitung dengan menggunakan Metode Largest Candidate Rules. Dalam metode ini dilakukan pendekatan penyeimbangan lini produksi berdasarkan waktu operasi terpanjang akan diprioritaskan penempatannya dalam stasiun kerja. Prinsip dasarnya adalah menggabungkan proses-proses atas dasar pengurutan operasi dari waktu proses terbesar. Sebelum dilakukan penggabungan, harus ditentukan dahulu, berapa waktu siklus yang akan dipakai. Waktu siklus ini akan dijadikan pembatas dalam penggabungan operasi dalam satu stasiun kerja. Berikut hasil pengolahan menggunakan Metode Largest Candidate Rules, dapat dilihat pada Tabel 8.

Tabel 8. Hasil Pengolahan Data Dengan Menggunakan Metode Largest Candidate Rules

\begin{tabular}{ccc}
\hline Stasiun Kerja & Waktu Siklus & Waktu Total \\
\hline 1 & 5 & \\
2 & 5 & 20 \\
3 & 10 & \\
\hline 9 & 15 & 20 \\
4 & 5 & 20 \\
\hline 12 & 20 & 19 \\
\hline 14 & 15 & 19 \\
7 & 4 & \\
\hline 6 & 13 & \multirow{2}{*}{20} \\
11 & 6 & \\
5 & 6 & \\
10 & 3 & \\
13 & 3 & \\
15 & 3 & \\
8 & 3 & \\
& Line Efficiency r.5 & \\
\cline { 2 - 3 } & Smoothing Index & 1.414214 \\
\cline { 2 - 3 }
\end{tabular}


Metode Line Balancing berikutnya yang digunakan untuk mengoptimalkan proses produksi di Sabrina collection yaitu J-Wagon. Metode Heuristik ini mengutamakan jumlah elemen kerja yang terbanyak, dimana elemen kerja tersebut akan diprioritaskan terlebih dahulu untuk ditempatkan dalam stasiun kerja dan diikuti oleh elemen kerja lain yang memiliki jumlah elemen kerja yang lebih sedikit. Berikut hasil pengolahan data dengan menggunakan Metode J-Wagon dapat dilihat pada Tabel 9 dan Tabel 10.

Tabel 9. Data Waktu Siklus Dan Jumlah Stasiun Kerja Yang Mendahului

\begin{tabular}{ccc}
\hline Stasiun Kerja & Waktu Siklus & Jumlah Stasiun Kerja Sebelumnya \\
\hline 1 & 5 & 14 \\
2 & 5 & 5 \\
3 & 10 & 5 \\
4 & 5 & 5 \\
5 & 6 & 4 \\
6 & 13 & 4 \\
7 & 4 & 4 \\
8 & 3 & 3 \\
9 & 15 & 3 \\
10 & 3 & 3 \\
11 & 6 & 2 \\
12 & 20 & 2 \\
13 & 3 & 2 \\
14 & 15 & 1 \\
15 & 3 & 0 \\
\hline Total & 116 &
\end{tabular}

Tabel 10. Hasil Pengolahan Data Dengan Menggunakan Metode J - Wagon

\begin{tabular}{ccc}
\hline Stasiun Kerja & Waktu Siklus & Waktu Total \\
\hline 1 & 5 & \\
2 & 5 & 20 \\
3 & 10 & 20 \\
\hline 12 & 20 & 20 \\
\hline 14 & 15 & 19 \\
4 & 5 & 19 \\
\hline 9 & 15 & \\
7 & 4 & \multirow{2}{*}{20} \\
\hline 6 & 13 & \\
5 & 6 & \\
\hline 11 & 6 & \\
8 & 3 & \\
13 & 3 & \\
15 & 3 & \\
10 & 3 & \\
& Line Efficiency & \\
\cline { 2 - 3 } & Smoothing Index & 1.414214 \\
\cline { 2 - 3 }
\end{tabular}

Dari hasil pengolahan data menggunakan Metode Rangked Positional Weights, Largest Candidat Rules dan J- Wagoon. Untuk Metode Rangked Positional Weights bahwa stasiun yang bisa dikelompokkan yaitu $(1 \& 3),(9 \& 2),(5,7,8, \& 10),(11,13,14)$ sehingga memotong jumlah stasiun kerja sebelum dilakukan pengolahan data jumlah stasiun 15 stasiun kerja setelah di lakukan pengolahan data menjadi 8 stasiun kerja dengan nilai Smoothing Index dan Line Efficiency sebesar 20 dan 82.857143. Untuk Metode Largest Candidat Rules Dari hasil pengolahan data, berhasil memotong jumlah stasiun kerja dari total jumlah awal sebanyak 15 stasiun kerja setelah diaplikasikan metode ini berhasil dipotong menjadi 6 stasiun kerja dengan nilai Line Efficiency dan Smoothing Index sebesar 72,5 dan 1,414. Stasiun kerja yang berhasil di kelompokkan adalah $(1,2,3),(9,4),(12)$, $(14,7),(6,11),(5,10,13,15,8)$ Dengan waktu total 20 menit. Dan untuk Metode J-Wagoon berhasil mengurangi stasiun kerja dari jumlah awal 16 stasiun kerja menjadi 6 stasiun kerja dengan nilai Line Efficiency dan Smoothing Index sebesar 72,5 dan 1,414. Stasiun kerja yang berhasil di kelompokkan adalah $(1,2,3),(12),(14,4),(9,7)(6,5)$, dan $(11,8,13,15,10)$ dengan waktu total 20 menit. 


\section{KESIMPULAN}

Dari penerapan pendekatan Line alancing, didapatkan metode yang paling baik diterapkan pada proses produksi di perusahaan Sabrina Collection yaitu Metode Largest Candidate Rules dan Metode J-Wagon, dengan waktu siklus sebesar 20 menit. Stasiun kerja dari jumlah awal 16 stasiun kerja menjadi 6 stasiun kerja dengan nilai Line Efficiency dan Smoothing Index sebesar 72,5 dan 1,414. Stasiun kerja yang berhasil di kelompokkan adalah $(1,2,3),(12),(14,4),(9,7)(6,5)$, dan $(11,8,13,15,10)$ dengan waktu total 20 menit. Dengan berkurangnya stasiun kerja, maka potensi bottleneck di beberapa stasiun kerja seperti di stasiun proses penjahitan dan stasiun kerja proses penyablonan juga dapat dikurangi.

\section{DAFTAR PUSTAKA}

[1] H. Purnomo, Pengantar Teknik Industri, Yogyakarta: Graha Ilmu, 2004.

[2] T. Baroto, Perencanaan dan Pengendalian Produksi, Cetakan Pertama, Ghalia Indonesia, Jakarta, 2002.

[3] Fogarty, Blackstone and Hoffmann, Production and Inventory Management, 2th ed., South-Western, 1991.

[4] V. Gasperz, Production Planning And Inventory Control. PT. Gramedia Pustaka Umum. Jakarta, 2004.

[5] A.H. Halim, Perencanaan dan Pengendalian Produksi: Keseimbangan Lintasan, Institut Teknologi Bandung, Bandung, 2003.

[6] J. Heizer, dan Barry Render, Operation Management, Buku 2, Edisi ke tujuh. Penerbit Salemba Empat. Jakarta, 2006.

[7] D. R. Wardhana, "Analisis Line Balancing Pada Bagian Sub Frame Motor Matic XXX Menggunakan Metode Rank Positional Weight”, Jurnal Ilmiah Teknik Industri, vol. 7, no. 3, pp. 191-198, 2019.

[8] R. B. Chase, Nicholas J. Aquilano and F. Robert Jacobs, Operations Management for Competitive Advantage, Ninth Edition, Irwin McGraw-Hill, Boston, 2001.

[9] Sipper and Bulfin Jr., Production Planning Control and Integrations, McGraw Hill, 1997.

[10] N. Kumar and Mahto, D., Assembly Line Balancing: A Review of Developments and Trends in Approach to Industrial Application, Global Journal of Researches in Engineering Industrial Engineering, Vol 13, Issue 2, Version 1.0, 2013.

[11] B. Andersen and Fagerhaug, T., Root Cause Analysis: Simplified Tools Techniques, American Society for Quality, Quality Press, Milwaukee, 2006. 